\title{
Pomen vrtičkarske dejavnosti v Ljubljani za posameznika, okolje in mesto
}

$\mathrm{V}$ besedilu je pomen vrtičkarske dejavnosti v Ljubljani obravnavan $s$ treh vidikov: $z$ družbenega in ekološkega vidika ter vidika mesta kot prostorske enitete. Vrtičkarstvo v mestu kot običajna urbana praksa zadeva več aspektov, ne le preskrbe s hrano, kot je poudarek tega besedila. Kot neformalna družbena dejavnost zadovoljuje mnoge potrebe posameznikov in se nanaša na kakovost življenja in bivalnega okolja. Slednje je pomembno tudi ob upoštevanju prostorskih vrednot in preferenc, saj v proučevanju vrtičkarstva kot družbenega pojava ugotavljamo kulturno specifični in družbeni pomen te dejavnosti za ljubljanske prebivalce. Vrtičkarstvo je torej ob ustreznih pogojih ter urejanju in nadziranju dejavnosti pozitivno v več vidikih, ne le za uporabnike, ampak tudi za mesto in okolje sámo, saj je pomemben del zelenega sistema mesta in $s$ tem pozitivne mestne podobe. Nesoglasja, do katerih je prišlo zaradi sanacije vrtičkarskih območij v Ljubljani, so zahtevala ustrezno reševanje problematike vrtičkarstva. Zaradi tega dejstva in da bi se preprečili problemi, ki potencialno izhajajo iz te dejavnosti, pa poudarjamo pomembnost in smiselnost vrtičkarstva, s poudarkom na prednostih, ki jih ta praksa prinaša.

Ključne besede: vrtičkarstvo, družbeni pojav, vrtičkarji, prostorska sociologija, Ljubljana, Slovenija 


\section{Uvod}

Pri proučevanju vrtičkarske dejavnosti v Ljubljani gre za obravnavanje kompleksne problematike. Zaradi neustrezne opredeljenosti vrtičkarske dejavnosti v mestnih načrtih in nezadostne količine območij, namenjenih temu, so se vrtičkarska območja spontano širila (zlasti med letoma 1984 in 1995, od takrat naprej pa sta površina in število vrtičkarskih območij nazadovala (Bole idr., 2009)). Razširjenost in razpršenost vrtičkov sta se izkazali kot problematični v mnogih vidikih. Če naštejemo le nekatere izmed teh, gre za probleme okoljevarstvenega značaja, za probleme stihijske in točkovne pojavnosti, nelegalnega zasedanja in prisvajanja prostora, ki je redka dobrina, za vidno motnjo $\mathrm{v}$ podobi mesta ter nazadnje za konfliktne razmere med vrtičkarji in mestnimi oblastmi zaradi sanacije določenih (problematičnih) lokacij. Z navedeno problematiko niso povezana le ravnanja vrtičkarjev, ampak tudi ravnanja akterjev v procesih reševanja problematike vrtičkarske dejavnosti.

V urbanem okolju je uspešno usklajevanje raznolikih interesov prebivalcev zapleteno in težko dosegljivo, zato pogosto prihaja do omejevanja identitet posameznikov na poti do samouresničitve. Popolnoma logično je sicer, da mesto usklajuje interese z možnostmi, pri tem pa prostor ureja prek določenih politik, zato delovanje posameznikov pri uporabi prostora ne more biti popolnoma prosto. Kljub temu skoraj povsod najdemo neformalne in spontane rabe prostora, številčnost teh pa s kompleksnostjo družb celo narašča. Tako se je tudi vrtičkarstvo v Ljubljani spontano razmahnilo, in ker ni bilo prave opredeljenosti območij in regulacije, tudi dolgo obdržalo na (večinoma nelegalno) prisvojenih območjih.

Sodobni trendi težijo h kakovostnemu oblikovanju grajenega in tudi odprtega javnega prostora, kar se povezuje s kakovostjo življenja, ki je v sodobnem času prav tako vse pomembnejša kategorija pri oblikovanju in urejanju prostora. Ena izmed legitimnih rab prostora $\mathrm{v}$ kontekstu mestnih zelenih površin je tudi vrtičkarstvo v mestu, kot to dokazujejo primeri tujih mest. Zato je marginalizacija te dejavnosti, v pričakovanju, da bo sčasoma izginila, naivna domneva, reševanje problematike z ustreznimi mehanizmi pa nujno potrebno, zato da mesto uspešno funkcionira in je okoljsko vzdržno. Če se spomnimo skupine vrtičkarjev, ki je $s$ protestom nasprotovala rušenju in sanaciji »svojih « vrtičkov, naletimo na očitna vprašanja: ali je imeti vrtiček v mestu res tako pomembno, ali je potreba po tem res tako velika in kje so vzroki zanjo ter zakaj se sanacijo doživlja kot napad, čeprav se je večina vrtičkov vzpostavila nelegalno in so zato sankcije pričakovane. Odgovori na ta vprašanja niso popolnoma preprosti in tako se v pojasnjevanju nastalih okoliščin in razlagi vzrokov zanje znajdemo $\mathrm{v}$ neprijetnem položaju. Ker pa se na tem področju v zadnjem času dogajajo določene spremembe (sanacija, opredelitev in opremljanje no- vih vrtičkarskih območij in podobno), je smiselno poudariti, kakšen pomen ima vrtičkarstvo $\mathrm{v}$ mestu in na katerih ravneh se to izraža.

Izhodiščna hipoteza se nanaša na pomen vrtičkarstva na treh ravneh. Vrtičkarska dejavnost je pomembna za družbo, zlasti za uporabnike te dejavnosti, saj ti prek nje zadovoljujejo svoje potrebe. Pri tej dejavnosti pa ne gre le za neposredno zadovoljevanje potreb uporabnikov, ampak tudi za širši pomen. Gre torej tudi za posredne posledice, ki vplivajo na vse meščane, te pa se izražajo zlasti pri okoljskih prednostih in pozitivnih vplivih na mesto. Vrtičkarska dejavnost je torej pomembna z ekološkega vidika in vidika trajnostnega razvoja, za mesto pa z estetskega in ekonomskega vidika kakovostnega bivanjskega prostora. $\mathrm{V}$ raziskavah o vrtičkarstvu se poudarja zlasti pomen, ki ga ima vrtičkarstvo za uporabnike, in sicer zlasti v ekonomskem oziroma eksistenčnem smislu, zato bomo poskušali poudariti tudi pomen, ki ga ima vrtičkarstvo še v drugih vidikih za družbo ter za okolje in mesto. Še zlasti je prezrt pomen, ki ga ima dejavnost za mesto, v katerem se pojavlja. Ob ustreznem delovanju ima namreč vrtičkarstvo veliko pozitivnih učinkov, čeprav se najpogosteje poudarjajo prav negativne posledice vrtičkarstva, zlasti iz okoljevarstvenega vidika. Zavedamo se, da v uvodu omenjeni problemi in dileme glede vrtičkarstva gotovo niso zanemarljivi, ampak ker niso osrednji del pričujoče obravnave, jih ne bomo poglobljeno obravnavali. Poudarek v tem besedilu gre zlasti prednostim, ki jih ima vrtičkarstvo glede na omenjene tri vidike. Hkrati pa je treba poudariti tudi pomembnosti ustreznega in strokovnega reševanja problematike vrtičkarstva, da potencialne prednosti, ki izhajajo iz te dejavnosti, dejansko pridejo do izraza.

\section{Opredelitev pojma vrtičkarske dejavnosti}

Vzroki za nastanek vrtičkarstva izhajajo iz družbenih, gospodarskih in prostočasnih potreb človeka, ki živi v mestnem okolju. Najprej se je pojavilo v industrijskih srednjeevropskih deželah, od koder se je razširilo v vse razvite države sveta (Jamnik idr., 2009). Glavna značilnost vrtičkarstva je multifunkcionalnost in dejstvo, da zadeva mnogo različnih urbanih sektorjev $\mathrm{v}$ svojem delovanju in rezultatih, ki jih bomo pojasnili v nadaljevanju, ter da je vključeno v urbani (ekonomski in ekološki) sistem in se uporablja s strani tega sistema (Mougeot, 2000).

Pri opredeljevanju vrtičkarstva naletimo tudi na določene probleme s konceptualizacijo. Pojav pridelovanja hrane in vrtičkarstva v urbanih okoljih je na podlagi tujih primerov opredeljen mnogo širše kot v Sloveniji, kjer je vrtičkarstvo po Odloku o urejanju in oddaji vrtičkov v zakup opredeljeno kot $\gg$ prostočasna dejavnost /.../ z namenom samooskrbe in negospodar- 
ske pridelave « (Ur. l. RS, št. 28/2009: 4014). Glede na to opredelitev se vrtičkarstvo pri nas, v ožjem smislu, v nekaterih določilih razlikuje od drugih opredelitev. Tako ni dovoljena pridelava hrane za trg, na teh območjih pa je prepovedana tudi reja živine ali prisotnost malih živali. V nasprotju s tem Luc Mougeot (2000) urbano kmetijstvo (ang. urban agriculture) opredeljuje precej široko, in sicer kot industrijo, ki vključuje številne dejavnosti, poleg tega pa ne govori o trgovanju per se, ampak o »distribuciji /.../ prehrambnih in neprehrambnih produktov /.../ (prav tam: 10), kar pomeni, da lahko vključuje tako formalno trgovanje kot tudi distribucijo znotraj neformalne mreže uporabnikov. Pri tem tudi ne omenja eksplicitno posameznih dejavnosti, ampak $s$ to opredelitvijo vključuje vse mogoče. Kajti le širše definicije urbanega kmetijstva poleg pridelovanja prehrambnih pridelkov in sadnega drevja $v$ mestih upoštevajo tudi različne vrste živinoreje, pridelave zdravilnih zelišč in okrasnih rastlin (Jacobi idr., 2000). Mougeot (2000: 10) v kontekstu te dejavnosti celovito opredeli tudi »/.../ ponovno uporabo zlasti človeških in materialnih virov, produktov in storitev znotraj in okrog urbanega območja ter $\mathrm{v}$ zameno oskrbovanje človeških in materialnih virov, produktov in storitev v to urbano območje «. $S$ tem se upoštevajo raznovrstne aktivnosti posameznikov in gospodinjstev v doseganju prehrambne preskrbljenosti in ustvarjanja dohodka in vpetost dejavnosti v urbani sistem. Ločitev urbanega kmetijstva od ruralnega se kaže prav v integriranosti prvega v urbani ekosistem.

Termin urbanega kmetijstva poudarjamo in ločujemo od pojma vrtičkarstva, ker je v glavnem opredeljen mnogo širše. Vrtičkarstvo, kot ga poznamo pri nas, pa umeščamo $v$ tri izmed tipov ali podkategorij urbanega kmetijstva, kot jih opredeljuje organizacija RUAF Foundation (internet 1). Tipi urbanega kmetijstva so:

- mikrokmetovanje $\mathrm{v}$ bivališčih in okrog njih - pridelovanje hrane in zelišč ter gojenje malih živali iz eksistenčnih razlogov, prostočasnih motivov in prehrambnih preferenc (po organski hrani), ki se izvaja zlasti na balkonih, okenskih policah, strehah ali v kleteh bivališč ter na dvoriščih, ki pripadajo stanovanjskim objektom;

- mestni vrtički (ang. community gardens) - vrtičkarstvo na javnih ali poljavnih površinah iz eksistenčnih razlogov, prostočasnih motivov in prehrambnih preferenc;

- institucionalno vrtičkarstvo - vrtičkarstvo šol, zaporov in bolnišnic, v katerih je glavni cilj preskrba članov institucij s hrano;

- majhna (pol)komercialna hortikulturna dejavnost - namen komercialne pridelave in samooskrbe revnih urbanih prebivalcev in primestnih malih kmetovalcev, ki pridelujejo zlasti zelenjavo ter tudi zelišča in sadje;

- majhna (pol)komercialna živinoreja in ribogojstvo - namen komercialne pridelave in samooskrbe primestnih malih kmetovalcev in urbanega srednjega razreda; ki prideluje živilske produkte;
- specializirano urbano kmetijstvo in gozdarstvo - delovanje zlasti tistih, ki so vključeni v različne projekte zaradi gojenja gob, rož lončnic in drevesnih nasadov, izključno za komercialno pridelavo in $\mathrm{z}$ močno težnjo intenzivnega pridelovanja in širjenja tehnične podpore;

- velika agropodjetja - večje kmetije primestnega značaja z zaposleno delovno silo; komercialna pridelava, pomembna vloga pri lokalni prehrambni preskrbi mesta;

- multifunkcionalne kmetije - manjše družinske ali večje kmetije primestnega značaja z zaposleno delovno silo; komercialna pridelava in ponudba nekaterih storitvenih dejavnosti.

Ljubljansko vrtičkarstvo lahko tako umestimo $\mathrm{v}$ kategorijo mikrokmetovanja znotraj bivalǐš in okrog njih, v kategorijo mestnih vrtičkov, ki je najbolj razširjena in hkrati tudi najbolj problematična oblika vrtičkarske dejavnosti v ljubljanskem mestnem prostoru, in v kategorijo institucionalnega vrtičkarstva, ki pa se v praksi vse bolj opušča. K mestnemu vrtičkarstvu torej ne prištevamo vrtov, ki so sestavni del individualnih ali vrstnih stanovanjskih objektov, ampak zgoraj omenjene oblike (slika 1). Problematika mestnih vrtičkov se nanaša tudi na nelegalnost velikega dela vrtičkov v Ljubljani, ki pomenijo potencialno tveganje za okolje in so posebej poudarjeni kot estetska degradacija mestne podobe, čeprav zadovoljujejo potrebe uporabnikov in tako zagotavljajo družbeni pomen, ne pa tudi drugih dveh omenjenih vidikov, kot bomo razložili v nadaljevanju.

Za ZDA in Evropo v splošnem velja, da vrtičkarstvo ni dejavnost le revnih slojev ali ruralnih imigrantov, ampak so vanjo vključena tudi mnoga gospodinjstva z visokimi dohodki in starejši mestni prebivalci. Največ mestnih vrtičkov je zlasti na prostih odprtih območjih v relativni bližini bivališča uporabnika ali neformalno ali v dogovoru s formalnim lastnikom zemljišča. $\mathrm{V}$ teh kategorijah gre $\mathrm{v}$ glavnem za samooskrbo, distribucijo presežka med sorodniki in sosedi ter tudi ( $\mathrm{v}$ nekaterih prime-

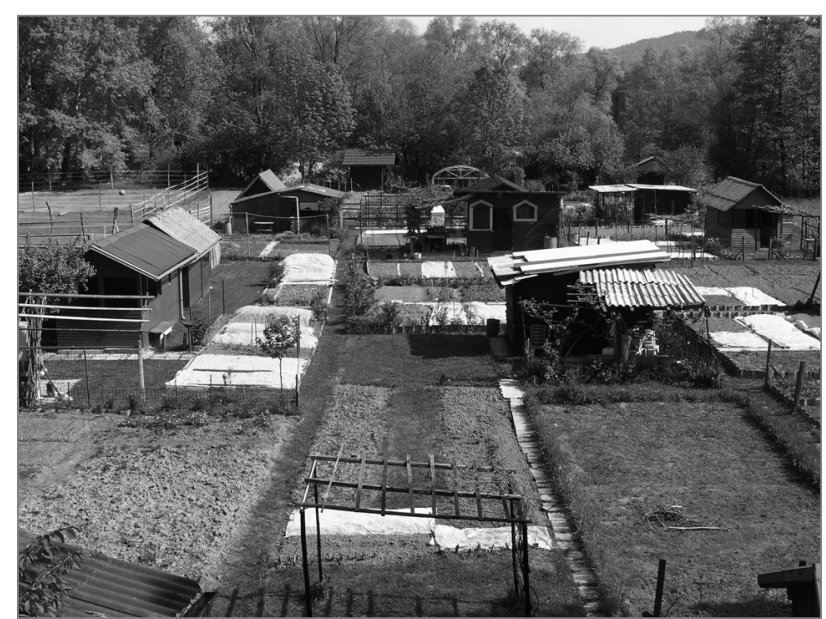

Slika 1: Vrtički v Ljubljani (foto: Aleš Smrekar) 
rih) za trgovanje s presežkom pridelka na lokalnih trgih. Te značilnosti se večinsko ujemajo z ljubljanskim vrtičkarstvom, le da je pri tem upoštevano, da sta trgovanje in reja živali pri ljubljanskih vrtičkarjih prej izjema kot pravilo in tudi formalno nista dovoljena.

\section{Pomen vrtičkarstva $z$ vidika posameznika kot uporabnika (družbeni vidik)}

Javne zelene površine, med katere spadajo tudi vrtičkarska območja, so se med časom umestile $\mathrm{v}$ mestno strukturo kot $»$ enakovredna, nenadomestljiva prostorska prvina « (Simoneti, 1997: 19). Iz tega izhaja dejstvo o družbeni funkcionalnosti zelenih površin, ki pomembno vplivajo na kakovost bivanja. Prebivalci so zaščitniško kritični do posegov na javnih zelenih površinah, sajse tudi njihovo zanimanje za njihovo dejavno rabo povečuje. Zato je potrebno tudi načrtno uveljavljanje načinov rabe prostora, sicer so te površine brez nadzora in vzdrževanja izpostavljene spremembi namembnosti (prav tam). Dodaten problem, posebej opazen v ljubljanskem primeru, se nanaša na neurbanizirana območja, ki postajajo prizorišče stihijskega razvoja nedovoljenih dejavnosti, med katerimi je najočitnejši primer prav vrtičkarstvo (Smrekar, 2007). Pomembnost zelenih površin $\mathrm{v}$ mestih pa potrjuje tudi dejstvo, da zeleni sistemi velikih evropskih mest iz leta $\mathrm{v}$ leto naraščajo zaradi naraščajočih potreb in zahtev meščanov (Simoneti, 1998). Preseneča tudi dejstvo, da moderno mesto ni izrinilo pridelave hrane iz urbanega družbenega dogajanja in da je vrtičkarstvo po svetu tako uveljavljena praksa, da se pojavlja v skoraj vseh metropolah razvitih držav in tudi držav $\mathrm{v}$ razvoju. Tako vrtičkarstvo ni ostanek preteklosti, saj zanimanje in vključevanje $\mathrm{v}$ to prakso narašča $\mathrm{z}$ večanjem mesta, niti ni del kulture imigrantov iz ruralnih okolij v mesta, za katere se pričakuje, da bodo sčasoma opustili svoje ruralne navade (internet 1). Vrtičkarstvo v mestu je integralni del urbanega sistema, pri tem pa je pomembno odrediti in urediti za to dejavnost primerna območja.

Če vrtičkarstvo obravnavamo v sklopu mestnih zelenih površin, kot je tudi opredeljeno v novih prostorskih načrtih, ne moremo zanemariti potreb urbanih prebivalcev po stiku z naravo, ki jih lahko zasledimo na več ravneh. Narava v mestu je sicer po mnenju Draga Kosa (2007: 158) le »bolj ali manj uspel nadomestek, ki le težko zadovolji temeljno potrebo po avtentičnosti, kar pravzaprav potreba po naravi je «. Mesto kot kulturni prostor namreč ne more nadomestiti naravnega prostora, lahko pa ga poskuša integrirati v urbani sistem ter prek uporabnosti vsaj do določene mere nadomeščati in zadovoljevati to potrebo urbanih prebivalcev. Za Ljubljano lahko rečemo, da je potreba po naravi oziroma stiku z naravo še posebej izražena, saj se v tako majhnem mestu, ki se nahaja v neposredni bližini podeželja ali vsaj podeželskih motivov in $\mathrm{v}$ katerem je nadpovprečno visok odstotek zelenih površin, nenehno poudarjajo zahteve po še več narave, ki pa jih mesto zaradi svojih omejitev ne more popolnoma zadovoljiti.

To nas pripelje do ugotovitve, da moramo upoštevati tudi kulturne vzorce znotraj slovenske družbe kot posebne dejavnike pri pomenu vrtičkarske dejavnosti za uporabnike. V Sloveniji gre namreč za »kulturno identifikacijo slovenstva s podeželjem « (Uršič in Hočevar, 2007: 59) oziroma lahko rečemo, da gre za povezovanje slovenskega načina življenja s podeželskim. Tako je tudi vrtičkarska praksa izraz tega, da mestni prebivalci ohranjajo svojevrstno povezanost $s$ podeželjem $s$ (po značilnostih) podeželskimi praksami, ki jih vnašajo v mestni prostor. $\mathrm{V}$ ljubljanskem primeru vrtičkarstva ta družbeni pojav povezujemo oziroma pojasnjujemo $\mathrm{z}$ vrednotami glede rabe prostora in prostorskih preferenc. $^{[1]} \mathrm{V}$ upoštevanju zaznane prevladujoče ruralne ideologije $\mathrm{v}$ slovenskem prostoru tako pojasnjujemo pomembnost dejavnosti z družbenega vidika. Zaznati je mogoče vztrajnost uporabnikov pri obdelovanju, vpliv tradicije in vrtnarjenje iz roda v rod ter vpliv »domačijstva « ${ }^{[2]}$ kot ene izmed praktičnih ideologij na posameznikovo navezanost na vrtiček. Protiurbane prostorske vrednote izkazujejo odklonilen večinski odnos do mesta, preference glede želenega kraja bivanja pa se $\mathrm{v}$ veliki večini nanašajo na podeželje. Tako lahko vrtičkarsko dejavnost pojasnjujemo tudi kot obliko prilagoditve na urbani bivanjski prostor v primerih, v katerih se kaže navezanost na podeželje. Kulturna tradicija pridelovanja hrane in preference po načinu bivanja s to možnostjo so razvidne iz

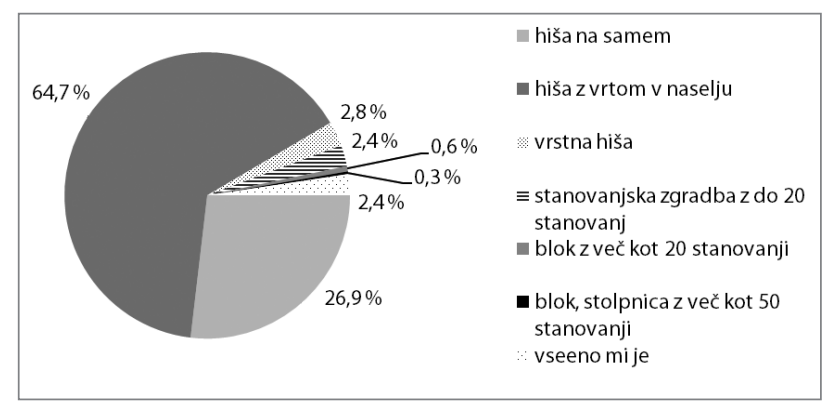

Slika 2: Bivanjske preference (vir: Hočevar idr., 2004)

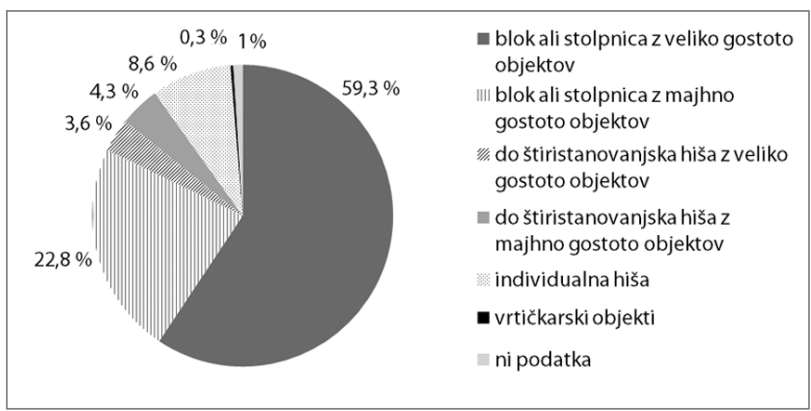

Slika 3: Vrsta bivalne enote vrtičkarjev v Ljubljani (vir: Jamnik idr., 2009) 
podatkov raziskave, v kateri kar $65 \%$ anketiranih na vprašanje $\gg$ Kje bi najraje stanovali, če bi imeli možnost za to? « odgovarja $\mathrm{z}$ odgovorom »Hiša z vrtom v naselju. « (Hočevar idr., 2004) (slika 2). Vrtički lahko tako pomenijo protiutež gosti prostorski ureditvi, saj tudi večina vrtičkarjev $(59,3 \%)$ prebiva v bloku ali stolpnici z veliko gostoto objektov, kot prikazuje slika 3 (Jamnik idr., 2009).

Po pregledu tujih raziskav lahko vidimo, da gre za mnoge družbene pomene vrtičkarske dejavnosti. Poleg najbolj očitnega, torej preskrbe s hrano, je mogoče zaznati še druge. Razlike med razvitimi državami in državami v razvoju so namreč precejšnje, zlasti se kažejo v vzrokih za vključevanje v dejavnost in potrebah, ki jih zadovoljuje - za države v razvoju pomeni vrtičkarstvo pomembno strategijo preživetja, zato se dejavnost $\mathrm{v}$ glavnem tudi spodbuja in omogoča pogoje zanjo, v razvitih državah pa je vse pomembnejši vidik rekreacije in prostega časa, čeprav sta oba vidika pomembna v obeh primerih. Urbana populacija vrtnari ali kmetuje v mestu, kjer možnosti za to niso otežene, torej če politični in ekonomski faktorji ustvarjajo pobude za to dejavnost (Nugent, 2000). Dobro urejene razmere in spodbujevalne pogoje je mogoče zaslediti v nekaterih državah v razvoju, v katerih je to lahko pomembna ekonomska komponenta in preživitvena strategija - na primer mesto Havana, v katerem se zelo spodbuja urbano kmetijstvo (Chaplowe, 1996) -, pa tudi v razvitih državah, kot je Japonska, v kateri lokalne oblasti v mestih iščejo in ponujajo nove ukrepe za ohranitev vrtičkarstva v mestih (Tsubota, 2007). Sicer pa so pobudo za vrtičkarstvo v mestih najpogosteje dale skupnosti, torej ali njihovi posamezniki, posamezne družbene skupine ali pa nevladne organizacije (Smit idr., 1996). V razvitih in visoko urbaniziranih mestih je vrtickkarstvo pogosto povezano z ovirami, delno tudi zaradi teženj po privatizaciji zapuščenih prostorov na mestih, na katera so se razširili vrtički, in potrebe po njihovi donosnejši rabi (primer mesta New York). Tako je značilnost vrtičkarstva prehodna raba prostora, saj se mora

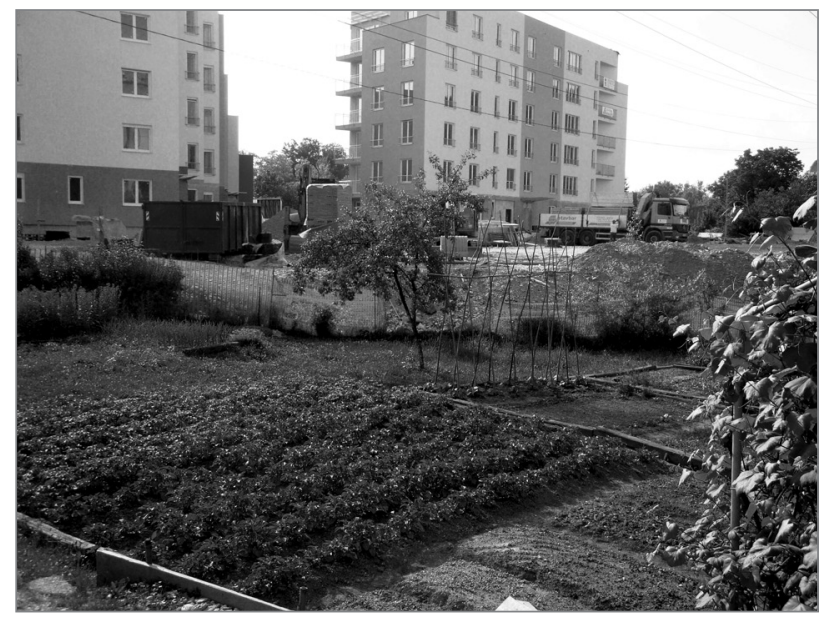

Slika 4: Črnuški vrtički neposredno ob gradbišču (foto: Karmen Bukvič) dejavnost pogosto umakniti gradnji ali drugim javnim programom, kar se dogaja tudi pri nas, sedaj pa je ta možnost tudi opredeljena v novem odloku (slika 4). Obstajajo pa tudi nekateri zgledni evropski primeri v zavarovanju območij, namenjenih vrtičkarstvu in njihovem urejanju, na primer mesta Berlin, Dunaj, London (Petts, 2001; Jamnik idr., 2009). V Sloveniji pa so se predvsem zanikali pomembnost vrtičkarstva in učinki, ki jih ima to na meščane. Šele ob spoznanju, kako močno je zasidrano vrtičkarstvo $\mathrm{v}$ družbi in povezano $\mathrm{z}$ vrednotami, se je pozornost namenila ureditvi in opredelitvi vrtičkarstva kot ene izmed legitimnih rab prostora.

Med pomembnimi družbenimi prednostmi Rachel Nugent (2000) izpostavlja diverzifikacijo gospodarstva, ekonomsko in kulturno specifično vedenje gospodinjstva in podobno. Značilno je tudi sodelovanje med vrtičkarji v izmenjavi pridelkov ali odpadkov (Jacobi idr., 2000; Mougeot, 2000), kar nakazuje na vzpostavljanje skupnosti, družbeno solidarnost in družbeno kohezijo. To pomeni, da vrtičkarji med drugim iščejo tudi priložnosti za družbene interakcije znotraj te neformalne dejavnosti. V zglednejših primerih, ki so bili opaženi v različnih urbanih okoljih kot neposredna posledica vrtičkarstva, so tudi primeri, v katerih vrtičkarstvo očisti mesto odlagalǐ̌č smeti, daje občutek koristnosti in spoštovanja starejšim občanom, reciklira gospodinjske odpadke in tako proizvaja prehrano, zvišuje okoljsko ozaveščenost in podobno (Bourque, 2000; internet 1). Čeprav nekatere izmed teh posledic niso preveč oprijemljive, zlasti če nanje gledamo kot na neposredne posledice, imajo kljub temu določeno veljavo. Tudi v Ljubljani imamo primer območja (območje ob Savi), na katerem so vrtičkarji predhodno sanirali odlagalǐšce odpadkov in si uredili vrtičke.

Družbena vloga in pomen mestnega vrtičkarstva sta vidna $\mathrm{v}$ večanju kakovosti prehrane in prehranjevanja ter pomenu za prehrambno varnost gospodinjstev, vključenih $\mathrm{v}$ to dejavnost neposredno in posredno, kar je še zlasti pomembno za revnejše sloje. Vrtičkarstvo pogosto pomeni dodaten vir dohodka, kadar gre za trgovanje, ali generiranje dohodka $\mathrm{z}$ varčevanjem pri izdatkih za prehrano. Tuji primeri poudarjajo tudi spodbujanje družbene vključenosti nekaterih, pogosto marginalnih družbenih skupin (na primer migrantov, hendikepiranih, nezaposlenih in podobno). Urbano kmetijstvo tako zagotavlja »komplementarno strategijo « pri zmanjševanju revšcine in višanju prehrambne varnosti $\mathrm{v}$ urbanih okoljih (internet 1), nanaša pa se še na veliko drugih vidikov. $Z$ obrazložitvijo potreb, ki jih lahko zadovoljuje vrtičkarska dejavnost, razlagamo tudi vidik pomembnosti vpliva dejavnosti na kakovost življenja meščanov in $s$ tem precejšen družbeni pomen vrtičkarske dejavnosti (Simoneti idr., 1997):

- Duševne potrebe, pri katerih gre za neposreden stik z naravo, možnost spreminjanja in vpliva na svoje okolje, estetsko zadovoljstvo v ustvarjanju in urejanju, delno tudi 
za potrebo po drobnem lastništvu. Vključimo pa lahko tudi način življenja, ki po mnenju Mirjane Ule (1998) ni nekaj nujnega za preživetje, je pa nujno potreben za posameznikovo samopodobo, in ker se vrtičkarstvo kaže tudi prek določenega načina življenja, se lahko ta potreba zadovoljuje tudi v okviru duševnih potreb. Pri navedbi duševnih potreb poudarjamo tudi pozitivnost pri spremljanju rezultatov lastnega dela uporabnikov in pomembnost primarne producentske vloge posameznikov, ki neposredno uživajo produkte svojega dela.

- Družbene potrebe, pri katerih gre predvsem za druženje, interakcijo z drugimi uporabniki, povezovanje v skupine ali organizirane oblike, kot so na primer vrtičkarska društva. V okviru družbenih potreb je pomemben tudi prosti čas, saj je vrtičkarstvo kot neformalna in dopolnilna utilitarna dejavnost prostočasna aktivnost.

- Fizične potrebe se nanašajo zlasti na rekreacijo, sprostitev in počitek.

- Eksistenčne potrebe pa se ne nazadnje nanašajo zlasti na ekonomski vidik, torej na konvencionalno ali ekološko pridelovanje hrane in oskrbo $s$ hrano, kar deloma pomeni tudi varčevanje pri odhodkih gospodinjstva. Nanaša pa se torej na kvantiteto in tudi na kakovost pridelane hrane za gospodinjstva, vključena v vrtičkarstvo.

- Zdravstvene potrebe, ki se nanašajo na rekreacijo v nasprotju s poklicnim (fizično) neaktivnim delom (Vastl, 2000). Tudi sami vrtičkarji poudarjajo ta vidik kot zelo pomemben prav zaradi fizične aktivnosti in duševnih prednosti. V okviru družbenih omrežij, ki se vzpostavljajo na vrtičkih, lahko poudarimo tudi vidik družbene opore, ki dokazano vpliva kot zaščita pred stresom in dejavnik dobrega počutja (Cobb, 1976, navedeno v Hlebec in Kogovšek, 2006). Posredno se zdravstveni vidik kaže tudi v izboljšanju okoljskih pogojev, ki vplivajo na zdravje meščanov.

Če podrobneje osvetlimo potrebo, iz katere izhaja estetski vidik problematike, Maja Simoneti idr. (1997) poudarjajo, da se lahko v vrtnarjenju in tudi v izgradnji objekta, ki je pogosto povezana $\mathrm{z}$ vrtičkarstvom dejavnostjo, meščani izživijo tudi »v ustvarjalnem smislu in v podoživljanju svojega dela « (prav tam: 7). Torej gre za svojevrstno estetsko izkušnjo in za zadovoljevanje uporabnikovih ustvarjalnih potreb, čeprav je prav to lahko » najbolj očitna in moteča značilnost posameznih vrtičkarskih območij « (prav tam: 18). To dejstvo navajamo zaradi zaznanega prevladujočega odklonilnega odnosa meščanov glede vrtičkarskih območij, v okviru katerega se na vrtičke gleda kot na nepotrebno motnjo $\mathrm{v}$ vidni estetski podobi mesta.

Zadovoljevanje predhodno naštetih potreb je v določenem pogledu glavni družbeni pomen vrtičkarske dejavnosti in hkrati pomeni najpomembnejše pozitivne posledice, ki ji ima ta za posameznika. Pomembnost družbenega pomena vrtičkarstva v mestih razvitih držav se namreč kaže prav v telesni in duševni sprostitvi, ki jo lahko dejavnost omogoča uporabnikom, in ne toliko v prehrambni produkciji. Pomemben pa je tudi vidik nizkocenovnih prostočasnih priložnosti, ki lahko pomenijo osnovo za začetek mikroizobraževalnih in pridobitnih projektov za mladino (internet 1). Pomen vrtičkarstva se poveča v kriznih časih (npr. državni nemiri, naravne katastrofe in podobno), v katerih se ljudje zatečejo $\mathrm{k}$ tej dejavnosti zaradi revščine, kot se je to zgodilo v Sarajevu in Bagdadu (Smit idr., 1996).

Po izsledkih raziskave Vrtičkarstvo v Mestni občini Ljubljana kot vir onesnaževal $v$ tleh, pridelani hrani in podzemni vodi se z vrtičkarstvom ukvarja nekaj odstotkov prebivalcev Ljubljane, ki jim ta dejavnost bolj kot ekonomsko nujo pomeni rekreacijo in sprostitev, zadovoljenje potrebe po neposrednem stiku z naravo in možnost pridelave zdrave hrane (Jamnik idr., 2009). Po mnenju Maje Simoneti idr. (1997) pa se pomen vrtičkarstva v mestih premalo poudarja kot pomembna ekonomska dejavnost. Čeprav je ekonomski vidik vrtičkarske dejavnosti v mestih pomemben, se v ljubljanskem primeru oblikuje smiselno vprašanje glede ekonomske komponente, ki se je poudarjalo ob sanaciji območja. Če kot primer navedemo opremljenost nekaterih vrtičkov, ki so spominjala bolj na počitniška naselja, na vrtičkarsko populacijo ni mogoče gledati kot na ekonomsko deprivirano. Po našem mnenju gre pri vrtičkarjih v največ primerih za kombinacijo motivov, na primer prostočasnih, rekreativnih in tudi ekonomskih. Sicer je tudi iz izsledkov raziskave razvidno, da le $9 \%$ vrtičkarjem

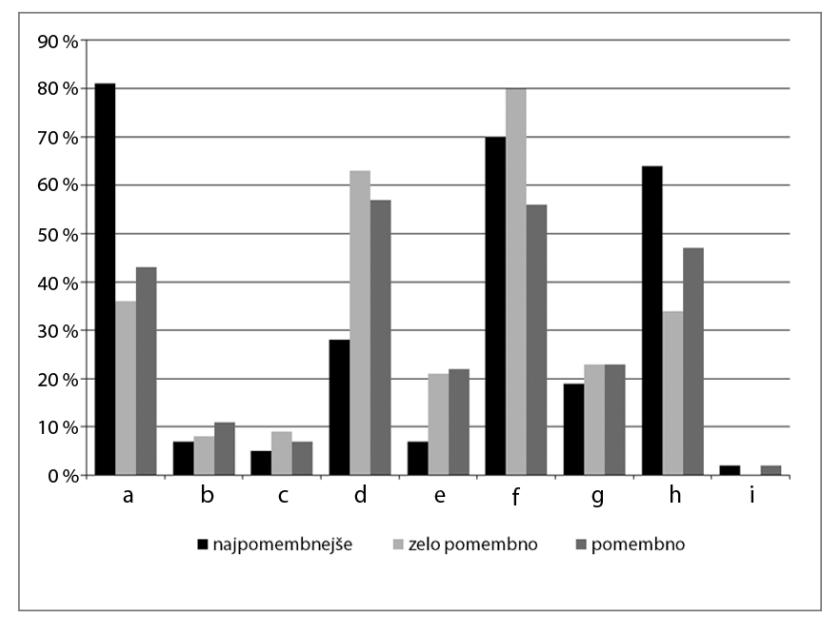

Opomba: (a) neposreden stik z naravo, (b) želja po aktivni rabi zelenih površin, (c) izživljanje ustvarjalnosti, estetsko zadovoljstvo, (d) fizična dejavnost, (e) preživljanje prostega časa z družino, (f) rekreacija, sprostitev, (g) pridelava hrane zaradi zmanjšanja življenjskih stroškov, (h) pridelava zdrave hrane, (i) drugo.

Slika 5: Glavni motivi za vrtičkarstvo med ljubljanskimi vrtičkarji (vir: Jamnik idr., 2009) 
vrtiček pomeni tudi pomembno ekonomsko sestavino oziroma pridelovanje hrane zaradi eksistenčnih razlogov (Jamnik idr., 2009) (slika 5). Ekonomski vidik se izraža na različnih ravneh, ne le z vidika ekonomskih prednosti za posameznika, ampak se poudarjajo tudi ekonomske prednosti za mesto, ki jih bomo navedli v nadaljevanju. Ekonomski vidik vrtičkarstva se kaže tudi v zmanjševanju stroškov, povezanih $s$ skrbjo za prehrano urbanih območij, in ekonomskem razvoju, zlasti v revnejših mestih, $v$ katerih ustvarja delovna mesta.

Med sanacijo vrtičkov v Črnučah, ki je povzročila veliko nezadovoljstva med vrtičkarji, so začeli ti poudarjati pomembne ekonomske prednosti te dejavnosti. Ker te subjektivne ocene ni mogoče zanemariti, se je gotovo upoštevala tudi v ponovnem opredeljevanju vrtičkarstva in določanju prednostnih kriterijev pri pridobitvi vrtička v uporabo. Dohodki gospodinjstva glede na odstotek povprečne neto plače tako pomenijo prednostni kriterij pri dodeljevanju vrtička v zakup. Poleg tega vse bolj prihaja $\mathrm{v}$ ospredje teza o potrebah zaradi gospodarske krize, zato ne moremo z gotovostjo trditi, kateri motivacijski dejavniki v tem trenutku prevladujejo. Dejstvo, da ekonomski ali preživitveni razlogi niso najpomembnejši, kot izhaja iz raziskave, pa ne bi smelo biti pomembno pri upoštevanju vrtičkarstva v mestnih načrtih ter opredeljevanju pomembnosti vrtičkarske dejavnosti za uporabnike in tudi za meščane. Vrtičkarstvo namreč združuje več pozitivnih vidikov dejavnosti, ki pomembno vplivajo na kakovost življenja meščanov v splošnem. $S$ tem mislimo predvsem na posredne posledice in prednosti tudi za nevrtičkarje, ki bodo opisane v prihodnjih poglavjih. Kajti pojavlja se vprašanje uporabnosti oziroma pomena vrtičkarskih površin za nevrtičkarje oziroma druge uporabnike javnih zelenih površin, saj se vrtički razlikujejo od drugih zelenih površin $\mathrm{v}$ mestu (parki, rekreacijske površine in podobno), ki so namenjene in dostopne vsem.

Pri tem, kako so vrtičkarska dejavnost in območja opredeljeni z novo vrtičkarsko politiko (Odlok o urejanju in oddaji vrtičkov v zakup ter Pravilnik za urejanje območij vrtičkov v Mestni občini Ljubljana), pa zaznavamo še eno pomembno dejstvo v proučevanju vrtičkarstva kot družbenega pojava. Gre za pojav prehoda iz refleksivnih krajev v bolj instrumentalne prostore. Če upoštevamo vse razsežnosti teh dveh tipov prostorov, lahko vidimo, da je prejšnje stanje izražalo refleksivnost, ki je omogočala tudi samouresničitev posameznika. Če navedemo nekaj značilnosti teh dveh oblik, gre za značilno znotrajsistemsko lastnost refleksivnih krajev, ki je po Marjanu Hočevarju (2000) raznovrstnost v praksah, medtem ko gre pri instrumentalnih prostorih zlasti za standardizacijo. Refleksivne kraje označujeta tudi razločljivost med sistemi in izrazita individuacija $\mathrm{v}$ procesih preobrazbe, pri instrumentalnih prostorih pa je prav nasprotno. Pri slednjih gre namreč za univerzalnost, procese preobrazbe pa določa globalizacija. Tako so instrumentalni prostori $\mathrm{v}$ razmerju z refleksivnimi homogeni, univerzalni, medtem ko se pri refleksivnih izražata heterogenost in partikularnost, kar se je posebej izražalo pri ljubljanskih vrtičkarskih območjih. Pri refleksivnih prostorih gre tudi za izraznost, torej za simbolno-estetsko ekspresivnost. Vrtičkarska območja so torej pred začetkom sanacijskih procesov izražala vse značilnosti refleksivnih krajev, kar je med drugim tudi posledica neregulacije. Z uveljavitvijo in predvsem upoštevanjem novega Odloka ter opremljenostjo vrtičkov v skladu s pravilnikom bo vrtičkarstvo standardizirano opredeljeno glede oblikovnih značilnosti in rabe. Če primerjamo z drugimi vrtičkarskimi območji v večjih metropolah razvitega sveta, bo torej tudi ljubljansko primerljivo z vidika vidne podobe, zlasti če upoštevamo, da procese preobrazbe instrumentalnih prostorov določa globalizacija.

Zaton refleksivnosti vrtičkarskih območij pa ni poudarjen le zaradi omejenega delovanja uporabnikov in dejstva, da bo dejavnost postala tudi legalizirana, območja pa zato urejena in regulirana s strani mestnih akterjev. Pomembno je tudi, da so sedaj postavljeni drugačni kriteriji za pridobivanje pravic do vrtička. Če upoštevamo, da je družbeni status prednostni kriterij, pa to pomeni tudi dejstvo, da bo potem vrtičke pridobil tisti del uporabnikov, ki jim to resnično pomeni ekonomsko nujo in morda ne toliko samouresničitve kot značilnosti refleksivnih prostorov. Dodatni razlog, ki pojasnjuje to domnevo, je tudi izraženo močno nezadovoljstvo dosedanjih vrtičkarjev nad določitvami prihodnjega vrtičkarstva (estetska pojavnost, velikost, cena in podobno), ki ne dopušča veliko individualnih intervencij in avtorskega izražanja. To sicer ne pomeni, da se ne bodo ponovno vzpostavili nekateri neformalni vrtički, ampak obstaja težnja k odpravljanju tega, čeprav so se regulacijski mehanizmi do sedaj v glavnem izkazali kot nedosledni.

V določilih glede vrtičkarstva tako obstaja visoka standardizacija ter vidna in tudi siceršnja uniformnost območij, kar poudarja na rigidnost urejevalnih pogojev. To predvsem pomeni, da za individualizem ni veliko možnosti. Očitke vrtičkarjev v zvezi z estetsko uniformnostjo vrtičkarskih območij lahko razumemo prek teze Zdravka Mlinarja (1993: 432), da je pretirana uniformnost $\gg$ neživljenjska blokada, ki onemogoča tudi popolnoma neškodljivo uveljavljanje individualne pobude in raznovrstnosti razpoložljivih virov«. Takšna uniformnost pa prihaja tudi v nasprotje s težnjo ohranjanja krajinske identitete. Maja Simoneti idr. (1997) predlagajo, da na trajnejših vrtičkarskih območjih, na katerih je dovoljena tudi izgradnja lope, katere estetski vidik je pomemben, oblikovalska določenost ne sme preprečevati individualizacije po posameznih vrtičkih, saj po njihovem mnenju ta območja pomenijo možnost za izražanje kreativnosti v urejanju prostora. Pomembna pri tem pa je lahko tudi prilagoditev posameznika na urbano bivanjsko okolje skozi načine estetizacije in $\mathrm{z}$ možnostjo vplivanja na 
svoje okolje. Tako omogočanje vrtičkarske dejavnosti v mestih deloma pomeni tudi manj sekundarnih bivališc in razpršene gradnje na obrobjih mest in na podeželju na račun omogočanja podeželskih praks in pristnih ruralnih prostorov $\mathrm{v}$ mestu ter $\mathrm{s}$ tem tudi zmanjšanje potrebe po tem. Nekaterim so bili vrtički podalǰ̌ki domov, najti je bilo mogoče tudi prava počitniška naselja, zato se sedaj teži k odpravljanju tega, saj to ni namen vrtičkarstva. Prav zaradi tega je ustrezna ureditev in opremljenost območij pomembna, hkrati pa omogočanje dejavnosti pomeni zviševanje kakovosti življenja urbanih prebivalcev.

\section{Pomen vrtičkarstva $\mathrm{z}$ vidika okolja}

Vrtičkarstvo je del urbanega ekološkega sistema. Zaradi ostankov fitofarmacevtskih sredstev in težkih kovin v prsti ali tleh in pridelani hrani ter onesnaževanja podzemne vode pomeni vrtičkarstvo tveganje za zdravje ljudi in okolje (Jamnik idr., 2009). Negativni okoljski vplivi, ki lahko izhajajo iz vrtičkarske dejavnosti, vključujejo tako že omenjeno vidno nečistočo, erozijo zemlje, uničevanje vegetacije, usedanje zemlje, izčrpanost vodnih virov in onesnaževanje naravnih virov (voda, zrak, prst). Pri tem so pomembne slabosti še nelegalna raba zemljiš̌c in vode, kraja pridelkov in tako naprej (Mougeot, 2000; $\mathrm{Nu}$ gent, 2000), v Ljubljani pa se soočamo tudi s problemi, ki presega obseg okoljskih tveganj, ki izhajajo iz vrtičkarstva. $\mathrm{V}$ tem kontekstu lahko nenadzorovano širjenje, nestrokoven izbor lokacij, ki niso primerne za vrtnarjenje, ter (nepravilna) uporaba različnih fitofarmacevtskih sredstev in njihova količina onesnaževalno vplivajo na naravne vire. Stanje, ki je nastalo na razširjenih vrtičkarskih območjih, lahko ogroža vrtičkarje oziroma uživalce vrtnin, ki so bile pridelane na območjih z dvomljivo kakovostjo zemlje. Problematične so na primer bližine velikih prometnic, odlagališča odpadkov, druga, po rabi degradirana tla in podobno. Ker pa se na območjih v Ljubljani ni izvajala le vrtnarska dejavnost, ampak med drugim črna gradnja, uporaba in odlaganje materialov oporečnih značilnosti, neurejenost odlagališč smeti in sanitarij ter podobno, je (bil) na nekaterih območjih negativen vpliv na okolje še večji.

Ti problemi nakazujejo nujnost in pomembnost urejanja ter reguliranja vrtičkarske dejavnosti zaradi okoljevarstvenih razlogov. Kljub temu se v večini raziskav poudarja, da vrtičkarstvo, ki je namenjeno samooskrbi, načeloma ne temelji na uporabi agrokemikalij oziroma naj bi bil njihov vnos manjši (Mougeot, 2000; Petts, 2001; Jamnik idr., 2009).

Pomen mestnih zelenih površin se torej nanaša na funkcije, ki jih imajo ta območja v osnovi, ne glede na človekove potrebe. To pomeni, da je smiselnost zelenega sistema tudi v določeni ekološki vlogi, pri kateri gre za pretok vrst iz naravnega v me- stno okolje in obratno (Kučan, 1994). Pri vrtičkarstvu torej ne gre le za urbano pridelavo hrane, saj tako skupnostno kot individualno pridelovanje hrane $\mathrm{v}$ mestih pomeni zadovoljevanje širših potreb urbane populacije, kot so trajnostni urbani razvoj in varovanje okolja (Jacobi idr., 2000). Prav trajnostni urbani razvoj v povezavi z vrtičkarstvom se pojavlja v več tujih študijah in raziskavah, poudarjajo pa se družbeni, ekonomski in okoljski vidiki trajnostnega razvoja. Pomembno je tudi, da lahko urbana produkcija hrane nadomešča uvoz hrane s podeželja ali iz tujine, ki je namenjen urbani potrošnji, in tako pripomore $\mathrm{k}$ večji samozadostnosti mesta v prehrambnem sistemu.

Med prednostmi, ki jih lahko ima vrtičkarstvo oziroma urbano kmetijstvo v širšem pomenu za okolje, je mogoče zaznati splošne prednosti zelenih mestnih sistemov in specifične prednosti, ki izhajajo neposredno iz vrtičkarske prakse, to so na primer ozelenitev mesta in izboljšanje biodiverzitete, izboljšanje kakovosti zraka in zmanjšanje vročine v urbanih okoljih oziroma izboljšanje mikroklime, zmanjšanje mestnih odpadkov ter ponovna uporaba organskih odpadkov in odpadne vode za vrtičkarstvo (Deelstra in Girardet, 2000; Jacobi idr., 2000; Petts, 2001). To pomeni tudi zmanjšanje ekološkega odtisa. Če te pomembne vidike bolje razložimo, gre za to, da naraščajoče mesto proizvaja vse več odpadne vode in organskih odpadkov. Pri tem lahko vrtičkarstvo pomeni konstruktivno rešitev, ki uporablja urbane odpadke kot produktivne vire pri svojem delovanju. Čeprav se vrtičkarstvo v mestu pogosto pojmuje kot nehigiensko, pa z načini uporabe odpadkov pri svojem delovanju potencialno izboljša higieno v mestu. Izboljšano upravljanje z mestnimi odpadki pomeni prehod od problema do produktivnega vira. Nadalje, pozitivno vpliva z ozelenitvijo in očiščenjem zapuščenih mestnih območij, ki tako postanejo del grajenega območja, kar dodatno ugodno vpliva na mikroklimo. Ker so tudi degradirana odprta in zapuščna mestna območja pogosto tista, ki služijo za »nelegalna odlagališča smeti« ter $\gg$ kraje kriminala in zdravstvenih problemov « (internet 1 ), je preobrazba takih območij v produktivne zelene površine nadvse smiselna. Pomemben vidik je tudi, da prehrana vse bolj katalizira okoljsko ozaveščenost, skrb in delovanje v tej smeri, saj ljudje »pomislijo, preden pogoltnejo « (Petts, 2001: 10). V splošnem pa se ta težnja kaže tudi v zanimanju za organsko prehrano in povečanju potrošnje organske prehrane.

Zelene površine v mestu pa so po Dragu B. Rotarju (1981) bolj nefunkcionalen dodatek utilitarni dejavnosti ter so namenjeni prostemu času in rekreaciji, saj znotraj sodobnega družbenoekonomskega sistema niso potrebni za produkcijo ali komunikacijo, vsaj ne neposredno. Ta teza zajema prevladujočo zavest o zelenih mestnih prvinah kot ne nujno potrebnih, čeprav je $\mathrm{z}$ razvojem sodobnih urbanih aglomeracij narava $\mathrm{v}$ mestu po- 
novno dobila svoj pomen in funkcijo $\mathrm{v}$ smislu zadovoljevanja določenih življenjskih potreb posameznikov, ki živijo v mestu. Tako se javne zelene površine dojemajo zlasti v kontekstu kakovosti življenja posameznikov, problem pri načrtovanju in investicijah, potrebnih za izvedbo načrtov, pa izhaja tudi iz te domneve nefunkcionalnosti, vsaj ekonomske oziroma potrošniške nefunkcionalnosti zelenih mestnih površin. Kljub temu vse bolj postajajo pomembne zahteve po mestih, ki se razvijajo v sožitju z naravo (primer Ecocity builders, internet 2), ki vključujejo naravne površine $\mathrm{v}$ urbane in jih ščitijo, stremijo $\mathrm{k}$ trajnostnemu razvoju in podobno. Raziskave poudarjajo, da »zelena in prijetna mesta pritegnejo investicije « (Petts, 2001: 15), zato je tudi ta ekonomski argument pomemben pri zagovarjanju ohranitve odprtih zelenih površin. Ker pa so potrebne investicije za ureditev dolgotrajno učinkovitih in okoljsko vzdržnih zemljišč za vrtičke je nujno poudariti tudi to, da slabo urejene razmere in neugodni pogoji oziroma pomanjkanje spodbujanja dejavnosti $s$ strani mestnih upravljavcev ne bodo privabili veliko interesentov, kar nadalje deloma vodi v zmanjšanje potrebe po vrtičkarstvu. Zmanjšana potreba pa ni argument za ohranitev zelenih delov mesta, ampak pomeni argument opredeljevanja teh predelov v druge namene. Ko postanejo ti deli zelenih površin zazidljivi, je njihova namembnost dokončno spremenjena. Zato je nujna domneva za pozitiven pomen, ki ga ima vrtičkarstvo za okolje, prav urejanje in reguliranje te sicer neformalne dejavnosti. Glavni pogoj je torej v podpori načrtovalcev oziroma ustreznih politikah glede dejavnosti in pravilno ravnanje $\mathrm{z}$ naravnimi viri. Urejanje te dejavnosti, ki z nepravilnim delovanjem potencialno negativno vpliva na uporabnike in naravne entitete, je nujno potrebno. Torej, ni potrebna le določena stopnja regulacije te neformalne dejavnosti, ampak tudi strokoven izbor lokacij, na katerih je vrtičkarstvo najprimernejše z ekološkega vidika in na katerih so kakovostne površine za pridelavo hrane. Pomembno je zavedanje, da urejeno in regulirano vrtičkarstvo pomeni veliko več okoljskih prednosti kot tveganj. K temu pa pripomore prav ustrezna opredelitev območij in pravilno okoljsko ravnanje uporabnikov.

\section{Pomen vrtičkarstva $\mathrm{z}$ vidika mesta}

Poleg pomena, ki ga imajo vrtičkarska območja za mestne prebivalce in okolje, se poudarja tudi pomen, ki ga imajo za mesto sámo. Kot pomemben del javnih zelenih površin dopolnjujejo strukturno ponudbo zelenega sistema in rekreacijskega potenciala ter pomembno soustvarjajo mestno podobo (Simoneti idr., 1997). Hkrati se od ostalih zelenih površin v mestih, ki so zlasti rekreacijskega in estetskega značaja, razlikujejo v produktivnosti in posameznikom pomenijo tudi (bolj ali manj pomembno) ekonomsko sestavino. Zaradi prostorskih proble- mov, kot so pojavnost in razširjenost vrtičkarstva na poljubnih območjih, in zaradi oblikovalskih problemov, ki so vodili $\mathrm{v}$ večinsko nesprejemanje dejavnosti $s$ strani širše javnosti, je ustrezno urejanje in reševanje problematike nujno še zlasti v korist mesta.

Ana Kučan (1994) poudarja morfološko vlogo zelenih površin $\mathrm{v}$ mestu kot vidno obogatitev mestne podobe. $\mathrm{Za}$ to vlogo lahko rečemo, da gre med drugim tudi za pomemben estetski vidik, saj gre za gradnjo mestnega tkiva in sanacijo degradiranih območij. Sicer pa je zlasti kvantitativni vidik zelenih površin po Kosovem (2008) mnenju tisti, ki določa vitalnost in $\gg$ zdravje « mesta, oblikovna kakovost pa je v tem pogledu drugotnega pomena. Ta teza sicer velja za druge vrste zelenih mestnih površin, medtem ko gre pri vrtičkarstvu za dejavnost, ki (kot kmetijska dejavnost) izrablja naravne vire, je produktivna in tako pomeni tudi tveganje zanje. Pri vrtičkarstvu je torej za okolje in podobo mesta pomembnejši kakovostni vidik območij, hkrati pa tudi zadostna količina ponujenih vrtičkov, zato da se preprečuje nastanek spontanih.

Vzpostavljena vrtičkarska območja v Ljubljani so bila pogosto predmet negativne kritike prav zaradi svoje vidne pojavnosti in so jih dojemali kot degradacijo mestne podobe. Hkrati pa vrtičkarji negativno ocenjujejo načrtovana vrtičkarska območja zaradi estetske nepomembnosti in prevelike uniformnosti. Prav podoba vrtičkov in podoba mesta na njihov račun je pomemben del problematike, kar se izraža tudi v določanju lokacije prihodnjih vrtičkov in regulacije spontanih vrtičkov. Kot poudarjajo mestne oblasti, »vrtički /.../ ne sodijo v ožje mestno središče, na vidno izpostavljene lokacije, v bližino območij kulturne dediščine in v bližino pokopališč « (internet 3 ). S spremembo lokacije vrtičkov oziroma $\mathrm{z}$ odstranjevanjem vrtičkov z nekaterih problematičnih lokacij (na primer Žale) se vidi težnja k izrinjanju te dejavnosti iz družbene zaznave. Pri določitvi novih vrtičkarskih območij ima lokalizacija kot preprečitev širjenja pojava pomembno vlogo. Pri tem gre tudi za zmanjš̌evanje družbenih napetosti, ki so nastale zaradi razmer na prejšnjih območjih. Opremljenost vrtičkarskih območij in posameznih vrtičkov je pri tem vidiku najpomembnejša, saj hkrati izkazuje osrednje vidne značilnosti in s tem estetski vidik dejavnosti. Uporabniki vrtičke dojemajo kot podaljške domov, zato tam med drugim odlagajo kose pohištva in materiale, ki jih $\mathrm{v}$ domovih več ne potrebujejo, hkrati pa iz poljubnih, pogosto odpadnih, materialov gradijo vrtne lope. Daljše zadrževanje, ki je prav posledica te percepcije podaljška doma, zahteva tudi več opremljenosti od preproste lope za shranjevanje orodja. To se sedaj poskuša preprečiti z oblikovanjem in izgradnjo enakih lop na vrtičkih, $s$ čimer bi se onemogočila individualna gradnja lop in opremljanje vrtičkov. Enotna podoba objektov za shranjevanje orodja na načrtovanih vrtičkarskih območjih bo tako delovala veliko zglednejše, kot je bilo (večinsko) stanje do sedaj. 
Primeri iz tujine pogosto poudarjajo tudi prazna, zapuščena ali drugače degradirana območja, ki jih začasno ali trajno nadomeščajo vrtički in tako izboljšujejo vidno podobo soseske. Vrtičkarstvo ima tako pomembne prednosti za mesto tudi v estetskem vidiku, ampak seveda ob načrtovani in regulirani rabi. Podoba mesta lahko pridobi kakovost $s$ količino in $\mathrm{z}$ urejenostjo mestnih zelenih površin, kar vključuje tudi vrtičkarske površine. Pomen izboljšane podobe mesta na račun vrtičkov pa bo v Ljubljani izrazit šele, ko bodo prva urejena in opremljena vrtičkarska območja zakupljena in v uporabi.

Ob upoštevanju, da pri vrtičkarstvu ne gre le za pridelovanje hrane, ampak za prostočasno in rekreacijsko dejavnost, se poudarja tudi kombinacija te dejavnosti z drugimi prostočasnimi aktivnostmi. Tako so na novih vrtičkarskih območjih igralne površine in igrala za otroke, kot prikazuje slika 6 . To omogoča tudi odprtost vrtičkarskih območij za nevrtičkarje in dviguje uporabnost teh površin. Najlažje in najučinkoviteje je, če mesto zagotavlja take ureditve ter $\mathrm{s}$ tem omogoča in ohranja skladno in celovito estetsko podobo.

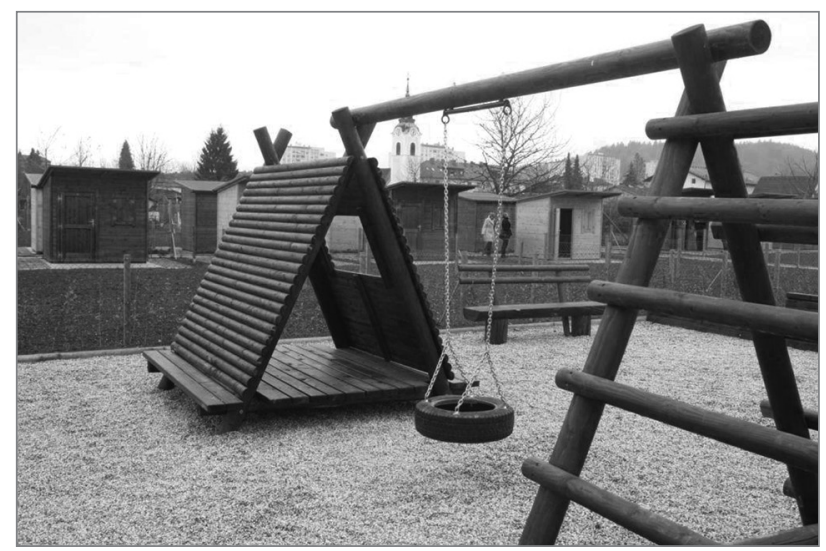

Slika 6: Vzorčni vrtički v Štepanji vasi in igrala za otroke (foto: Miha Fras)

Vrtičkarstvo dviguje tudi ekonomsko vzdržljivost mest in prispeva $\mathrm{k}$ trajnostnemu razvoju. Že omenjena uporaba mestnih odpadkov kot produktiven vir v vrtičkarski dejavnosti pripomore $\mathrm{k}$ zmanjšanju stroškov mesta, povezanih z upravljanjem z odpadki. Glede pomena, ki ga imajo vrtički v visoko urbaniziranih metropolah, poudarjamo tudi tezo o stabiliziranju in revitalizaciji soseske z vrtički, saj se lahko sčasoma dviguje tudi vrednost posesti (Petts, 2001). To dejstvo je lahko pomemben spodbujevalnik takrat, ko se mestni upravljavci odločajo o morebitnem investiranju v vrtičke. Soseske z vrtički namreč izkazujejo pozitivno podobo. Pomembno pa je tudi to, da estetiziranje območja določene neformalne dejavnosti, kot je vrtičkarstvo, pripomore $\mathrm{k}$ boljši sprejemljivosti širše javnosti, kar pomembno pozitivno učinkuje na družbene odnose. Tako lahko tudi zmanjšuje oziroma vpliva na nekatere negativne učinke, kot so $\mathrm{v}$ tem primeru stigmatizacija uporabnikov, marginalizacija dejavnosti in podobno.

\section{Sklep}

V obravnavanju vrtičkarstva kot družbenega pojava sem to neformalno družbeno dejavnost proučevala na treh ravneh $-s$ stališča posameznika, okolja in mesta. Zlasti zadnji kategoriji se sicer v nekaterih vidikih prepletata, kljub temu pa je mogoče prepoznati določene pomembne značilnosti kot posamezne vsake od kategorij. Ker je fokus razprave ravno sociološki, sem družbenemu vidiku namenila največ pozornosti, pri tem pa se mi je zdelo pomembno poudariti, da ni le posameznik in s tem družba, ki pridobi na račun spodbujanja oziroma vsaj omogočanja vrtičkarske dejavnosti, ampak so pozitivne posledice opazne tudi na ravni okolja in mesta kot prostorske entitete.

Ob upoštevanju potreb urbanih prebivalcev je načrtovanje kakovostnih zelenih površin v mestih svetovna težnja, saj ta vidik pomembno vpliva na kakovost življenja posameznika. Vrtičkarstvo pa ima prednosti tudi za okolje, in sicer z ekološkega vidika, za mesto pa z estetskega, ekonomskega in družbenega vidika. Skratka, globlji pogled na vrtičkarsko dejavnost odkriva ne le preskrbo s hrano, ampak tudi mnoge druge pomembne vidike, ki so v družbenem kontekstu pomembni in jih je treba proučevati. Tako ne zadeva le prehrane in prehrambne varnosti vključenih $\mathrm{v}$ to dejavnost, ampak tudi družbeno inkluzijo, solidarnost, stik z naravo in druge pomembne prednosti za posameznika. Širši družbeni pomen dejavnosti pa zajema še trajnostni razvoj, ozelenitev mest $s$ produktivnimi zelenimi površinami, prenovo degradiranih predelov mesta in pozitivno podobo mesta.

Največji pomen vrtičkarstva in hkrati njegovo bistvo je v tem, da njegov obstoj v urbanem okolju vpliva na lokalno ekonomijo, okolje in družbene odnose in lahko prispeva $\mathrm{k}$ pestrosti mesta, lahko pa pomeni odmik od tega in povzroča zdravstvena tveganja in napačno ravnanje $z$ redkimi viri. Zaradi potencialnih ekoloških in drugih problemov je urejanje dejavnosti s strani mestnih oblasti nujno potrebno. Ker pa vrtičkarstvo zadovoljuje zlasti duševne potrebe in se, kot je bilo ugotovljeno, nanaša na prosti čas in rekreacijo, je pomembno tudi sodelovanje javnosti oziroma uporabnikov v procesih urejanja vrtičkarske dejavnosti. To dejstvo poudarjam, ker problematika vrtičkarstva v Ljubljani zajema tudi preveč formalistične pogoje pri urejanju dejavnosti, s katerimi niso zadovoljni prav vrtičkarji. Napačna domneva, da bo večji nadzor pomenil tudi večjo disciplino, pripelje do ugotovitve, da bi ob sodelovanju javnosti pri urejanju vrtičkarstva na račun manj formalističnih pogojev prišlo do večje discipline, ki bi izhajala v pozitivnejših vidikih, to je v zadovoljstvu uporabnikov in občutku soodgovornosti za prostor, kar izvira prav iz sodelovanja oziroma integriranosti uporabnikov v procesu preobrazbe prostora.

Za optimizacijo pozitivnih učinkov na okolje in mesto, ki izhajajo iz vrtičkarstva, morajo biti izbrana ustrezna območja, ki so 
tudi primerno opremljena, dejavnost pa regulirana. Sicer z vidika posameznika in nekaterih njegovih potreb (zlasti duševnih in družbenih potreb), ta pogoj ni nujno potreben. Popolnoma logično pa je, da se ti dejavniki prepletajo in povezujejo - tako na primer ni zdrave hrane brez ustreznega ravnanja z redkimi viri ter strokovne določitve primernih in kakovostnih območij in podobno.

Karmen Bukvič

Videm pri Ptuju, Slovenija

E-pošta: bukvic.karmen@gmail.com

\section{Opombe}

${ }^{[1]}$ Vrednote prostora in okolja (glej Hočevar idr., 2004).

${ }^{[2]}$ Ena izmed praktičnih ideologij, ki je bistvena za slovenski prostor, je po Rotarju (1985) »domačijstvo«, ki je po njegovem mnenju ena od različnih protiurbanih ideologij, ki so se izoblikovale v preteklosti zaradi daljšega neobstoja nacionalne države ter so bile namenjene družbenemu povezovanju in mobilizaciji družbene zavesti Slovencev v kriznih obdobjih.

\section{Viri in literatura}

Bole, D., Breg Valjavec, M., Erhartič, B., Kladnik, D., Polajnar, K., in Smrekar, A. (2009): Presoja primernosti načrtovanih vrtičkarskih območij v Ljubljani [Assessing the suitability of planed garden-plot areas in Ljubljana]. Urbani izziv, 20(1), str. 53-67 [175-189].

Bourque, M. (2000): Policy options for urban agriculture. Dostopno na: http://www.trabajopopular.org.ar/material/Theme5.pdf (sneto 18. 5. 2009).

Chaplowe, S. G. (1996): Havana's popular gardens: Sustainable urban agriculture. Dostopno na: http://www.cityfarmer.org/cuba.html (sneto 8. 12. 2009).

Deelstra, T., in Girardet, H. (2000): Urban agriculture and sustainable cities. Dostopno na: http://www.trabajopopular.org.ar/material/ Theme2.pdf (sneto 18. 5. 2009).

Hlebec, V., in Kogovšek, T. (2006): Merjenje socialnih omrežij. Ljubljana, Študentska založba.

Hočevar, M. (2000): Novi urbani trendi: Prizorišča v mestih - omrežja med mesti. Ljubljana, Univerza v Ljubljani, Fakulteta za družbene vede.

Hočevar, M., Kos, D., Verlič-Christensen, B., Trček, F., in Uršič, M. (2004): Vrednote prostora in okolja. Raziskovalno poročilo. Ljubljana, Univerza v Ljubljani, Fakulteta za družbene vede, Center za prostorsko sociologijo.

Internet 1: http://www.ruaf.org/ (sneto 10. 11. 2009).

Internet 2: http://www.ecocitybuilders.org/ (sneto 4. 1. 2010).

Internet 3: http://www.ljubljana.si/si/zivljenje-v-ljubljani/ v-srediscu/277/detail.html (sneto 4. 1. 2010).

Jacobi, P., Drescher, A. W., in Amend, J. (2000): Urban agriculture - justification and planning guidelines. Dostopno na: http://www.cityfarmer. org/uajustification.html (sneto 18. 5. 2009).
Jamnik, B., Smrekar, A., in Vrščaj, B. (2009): Vrtičkarstvo v Ljubljani. Ljubljana, Založba ZRC.

Kos, D. (2007): Neurbana nacija. V: Čerpes, l., in Dešman, M. (ur.): 0 urbanizmu, str. 137-163. Ljubljana, Krtina.

Kos, D. (2008): Narava v mestu ali mesto v naravi? [Nature in the city or the city in nature?]. Urbani izziv, 19(2), str. 5-9 [129-132].

Kučan, A. (1994): Zeleni sistem Ljubljane. Urbani izziv, 6(26-27), str. 65-72.

Mlinar, Z. (1993): Prostorski nered kot izraz (ne)moči posameznika in sistema. Teorija in praksa, 30(5-6), str. 427-434.

Mougeot, L. J. A. (2000): Urban agriculture: Definition, presence, potentials and risk. Dostopno na: http://www.trabajopopular.org.ar/ material/Theme1.pdf (sneto 18. 5. 2009).

Nugent, R. (2000): The impact of urban agriculture on the household and local economies. Dostopno na: http://www.trabajopopular.org. $\mathrm{ar} /$ material/Theme3.pdf (sneto 18. 5. 2009).

Odlok o urejanju in oddaji vrtičkov v zakup. Uradni list Republike Slovenije št. 28/2009. Ljubljana.

Petts, J. (2001): Urban agriculture in London. Dostopno na: www. euro.who.int/document/e72421.pdf (sneto 8. 12. 2009).

Pravilnik za urejanje območij vrtičkov v Mestni občini Ljubljana. Uradni list Republike Slovenije št. 83/2009. Ljubljana.

Rotar, D. B. (1981): Pomeni prostora: Ideologije v urbanizmu in arhitekturi. Ljubljana, Delavska enotnost.

Rotar, D. B. (1985): Risarji: učenjaki: Ideologije v urbanizmu in arhitekturi. Ljubljana, Delavska enotnost.

Simoneti, M. (1997): Mestne zelene površine: med ljubiteljstvom in stroko. Ljubljana, Znanstveno in publicistično središče.

Simoneti, M. (1998): Je mestne krajine potrebno varovati? [Should urban landscapes be protected?]. Urbani izziv, 9(2), str. 45-50 [131-134].

Simoneti, M., Bevk, J., Pintar, M., Zupan, M., Gajšek, P., Golobič, M., idr. (1997): Usmeritve in pogoji za nadaljnji razvoj vrtičkarstva $v$ Ljubljani. Poročilo o razvojno-raziskovalni nalogi. Ljubljana, Ljubljanski urbanistični zavod.

Smit, J., Ratta, A., in Nasr, J. (1996): Urban agriculture: Foods, jobs and sustainable cities. New York, UNDP.

Smrekar, A. (2007): Stihijski (ne)razvoj neurbaniziranega dela mesta na primeru Ljubljane. Dela, 28, str. 341-357.

Tsubota, K. (2007): Urban agriculture in Asia: Lessons form Japanese experience. Dostopno na: http://www.agnet.org/library/eb/576/ (sneto 8. 12. 2009)

Ule, M. (1998): Stilizacija vsakdanjega življenja. Družboslovne razprave, 14(27-28), str. 26-32.

Uršič, M., in Hočevar, M. (2007): Protiurbanost kot način življenja. Ljubljana, Univerza v Ljubljani, Fakulteta za družbene vede.

Vastl, N. (2000): Vrtičkarstvo. Specialistična naloga. Ljubljana, Univerza v Ljubljani, Fakulteta za arhitekturo. 